Case Report

\title{
Challenge in the Management of Twin Pregnancy with Anencephaly of One Fetus in a Low- Income Country: A Case Presentation
}

\author{
Romaric Joel Momo ${ }^{1}$, Julius Dohbit Sama ${ }^{1}$, Esther Meka ${ }^{1}$, Mazou Ngou Temgoua ${ }^{2, *}$, \\ Pascal Foumane ${ }^{1}$ \\ ${ }^{1}$ Department of Obstetrics and Gynecology, Faculty of Medicine and Biomedical Sciences, University of Yaoundé, Yaoundé, Cameroon \\ ${ }^{2}$ Public Health Department, Faculty of Medicine and Biomedical Sciences, University of Yaoundé, Yaoundé, Cameroon
}

\section{Email address:}

centrebfm@yahoo.fr (R. J. Momo), dohbit@yahoo.fr (J. D. Sama), estherum@yahoo.com (E. Meka), neurotemgoua@yahoo.fr (M. N. Temgoua), Pfoumane2004@yahoo.fr (P. Foumane)

${ }^{*}$ Corresponding author

\section{To cite this article:}

Romaric Joel Momo, Julius Dohbit Sama, Esther Meka, Mazou Ngou Temgoua, Pascal Foumane. Challenge in the Management of Twin Pregnancy with Anencephaly of One Fetus in a Low- Income Country: A Case Presentation. Journal of Gynecology and Obstetrics.

Vol. 7, No. 3, 2019, pp. 81-84. doi: 10.11648/j.jgo.20190703.15

Received: March 11, 2019; Accepted: April 23, 2019; Published: June 11, 2019

\begin{abstract}
Anencephaly of one twin is a frequent congenital abnormality in a twin pregnancy and it's associated with a poor prognosis of this pregnancy. In developed countries, the goal standard management calls for an interventional fetal medicine either by injection of a cardiotoxic or by intervention on the umbilical cord. Another option is an expectative management with strict follow-up of pregnant women and delivery organized in a level 3 maternity. There is still a challenge in the management of such high risk pregnancy in low income countries. A 37 years-old female, G3P2002, referred from a clinic for the better management of a 28 weeks and 4 days twin pregnancy in labor. Obstetrical ultrasonography realized in the second trimester revealed dichorionic-diamniotic pregnancy and the presence of anencephaly with hydramnios of one twin. The expectative approach was adopted for the management of this high risk pregnancy, unfortunately the death of the fetus occurred despite all the care provided. This case brings to lamp light the difficulties encountered in providing standard obstetrical care for high risk pregnancies in resource limited settings.
\end{abstract}

Keywords: Anencephaly, Twin Pregnancy, Low Income Country

\section{Introduction}

A multiple pregnancy is a medical condition usually associated with malformations. The risk is about 1.6 to 2 times comparing to a normal intra-uterine singleton pregnancy [1]. The malformation mainly involves one of the twins giving the possibility of saving the second fetus [1]. Anencephaly is the most frequent malformation seen in twin pregnancies besides cardiac and renal defects; frequently encountered malformations in twin gestations [2]. It can affect the prognosis of the pregnancy and necessitate a higher technical platform and an expert in fetal medicine. There are two classical options for its management:expectative management and selective exclusion of malformed fetus [3]. Many studies reveal the superiority in terms of duration of pregnancy and fetal prognosis of the normal twin when the selective exclusion of the anencephalic twin is employed [3]. The marked improvement in fetal medicine in developed countries has contributed to increase in the prognosis of such pregnancies, compared to less-developed countries where case series reveal a lower prognosis [4]. This case exposes the challenges in the management of such pregnancies in low income countries. 


\section{Case Presentation}

A 37-years-old patient, G3P2002, referred from a clinic for the better management of 28 weeks and 4 days of gestation twin pregnancy in labor. The first prenatal consultation took place at 14 weeks, without folic acid prophylaxis. Three consecutive obstetrical ultrasounds were performed at 16, 22, and 26 weeks of pregnancy, had revealed and confirmed a dichorionic-biamniotic pregnancy and the presence of anencephaly with hydramnios of one twin. But the other twin didn't have any abnormalities in all obstetrical ultrasounds carried out. The Expectative management method was adopted because of limited resources with monthly follow-up of the pregnancy. At 26 weeks the patient presented with a history of uterine contractions-labour type in character, nature, intensity and frequency, and after clinical examination, a diagnosis of active phase of premature labor was made and delivery occurred 3 hours later. The anencephalic twin was dead at birth while the APGAR of the second was 4/ 5 in the first and five minutes post birth. These twins had presented with no visible malformations, but died 2 hours later in a context of acute respiratory distress.

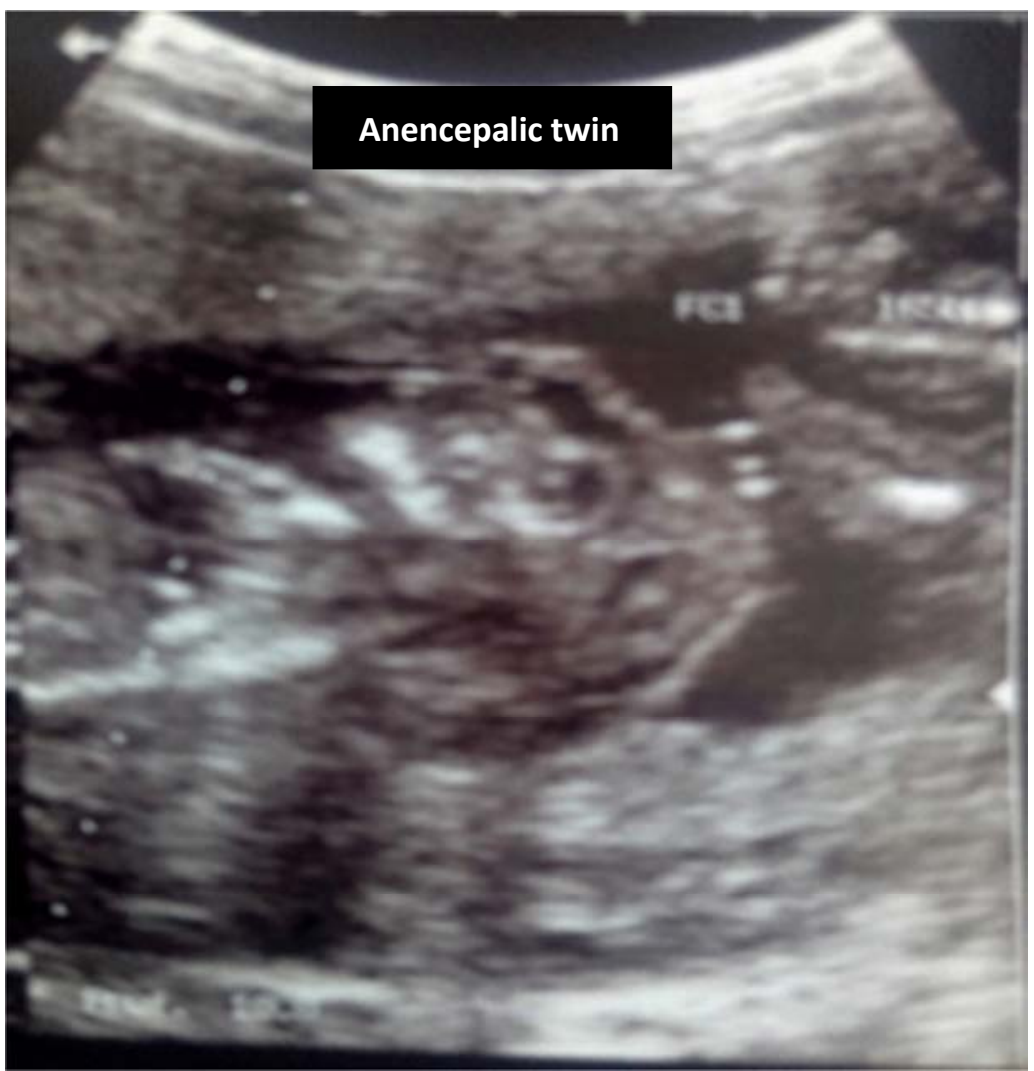

Figure 1. Second trimester obstetrical echography showing the anencephalic twin with the absence of skull and only presence of lower part of face.

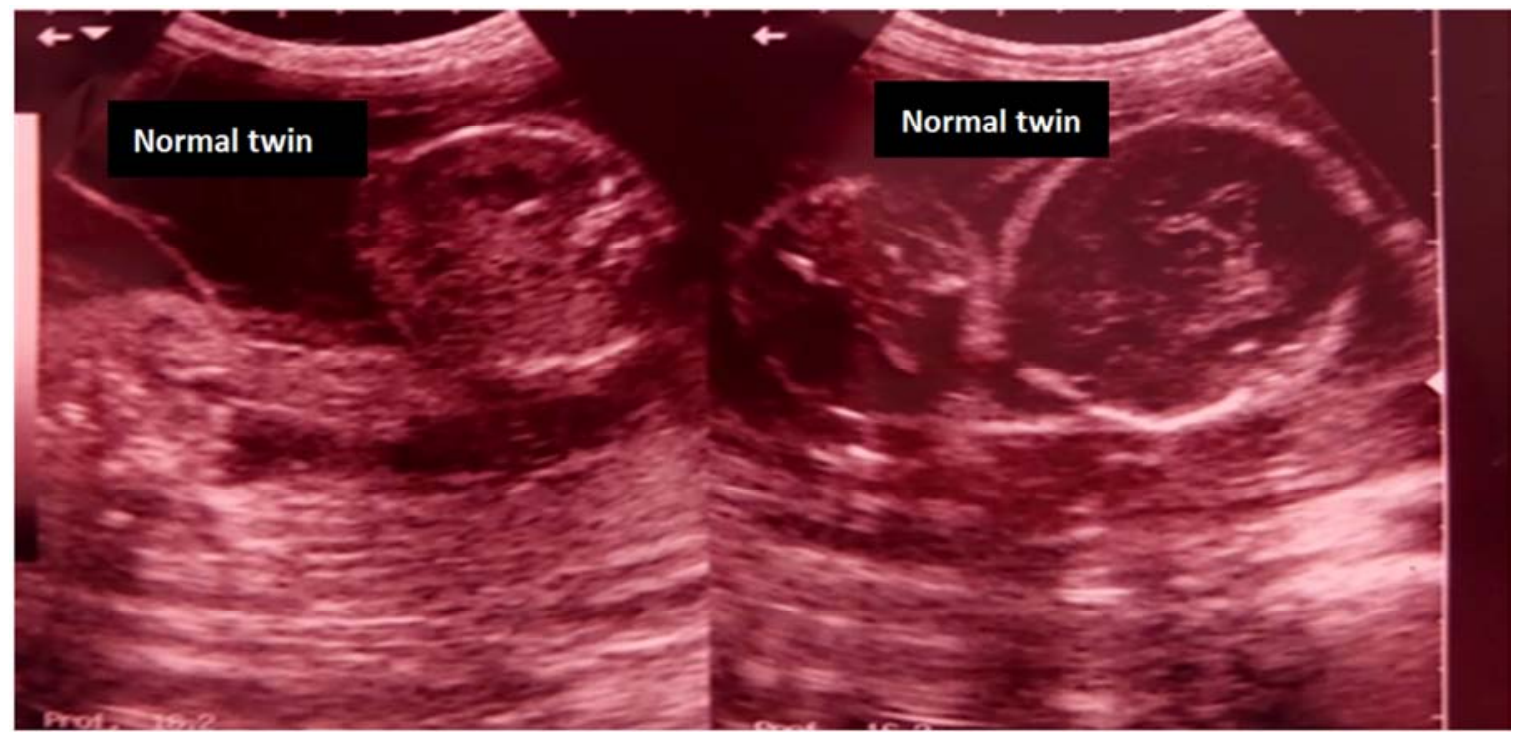

Figure 2. Echography of the normal twin at 22 weeks without cerebral abnormalities. 


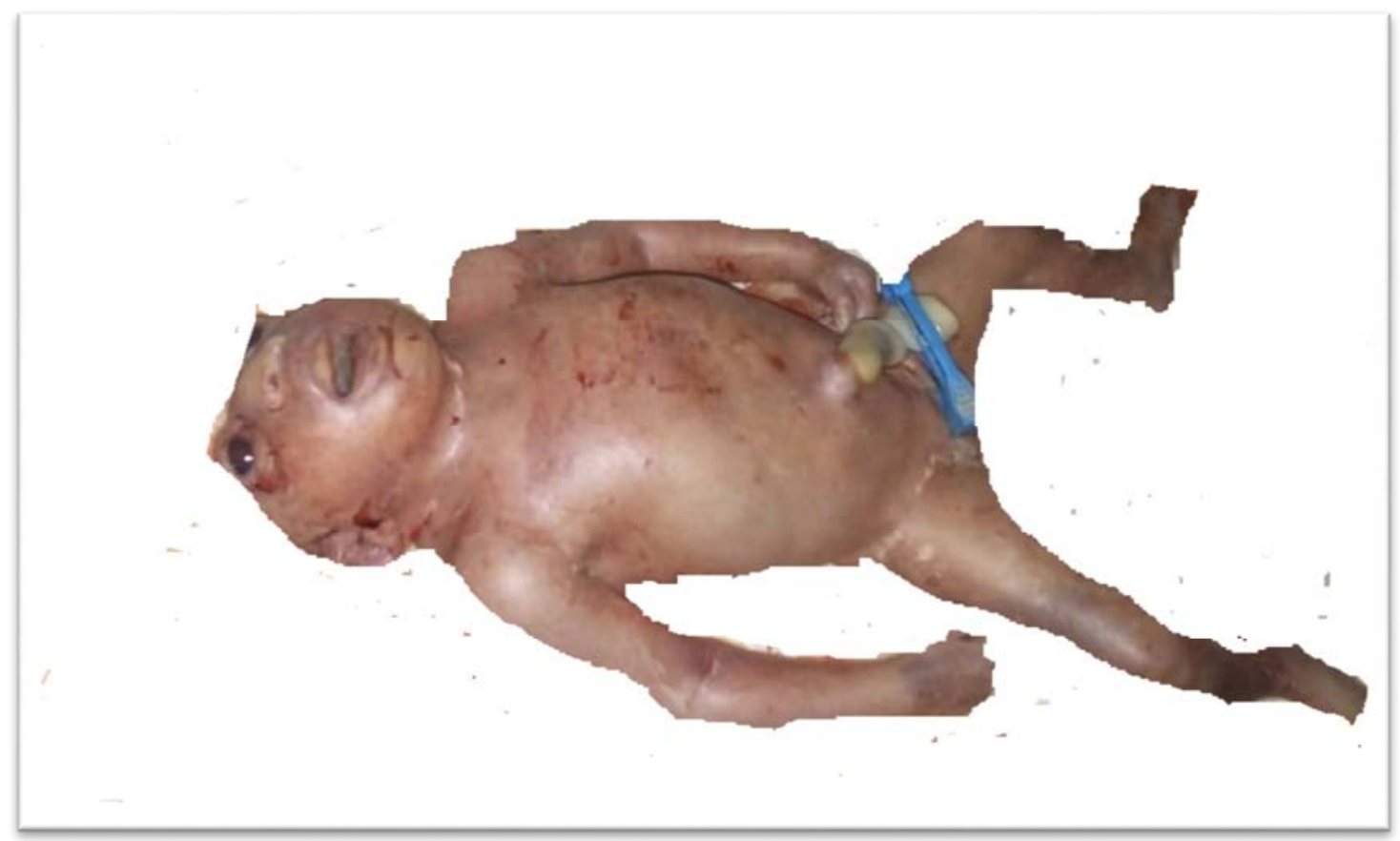

Figure 3. Macroscopical image of the anencephalic twin at birth.

\section{Discussion}

Anencephaly is a clinical form of neural tube defect. One of the risk factors is the folic acid deficiency that was presumed in our patient who didn't take the prophylaxis. Other risk factors were low socio economic level, absence of prenatal contact and in some studies fenugrec consumption in pregnancy [5] This abnormality is one of the most frequent malformations in twin pregnancy like cardiac and renal defects [2]. Amadaou A et al found that the clinical frequency of Anencephaly was $5.5 \%$ in all twin pregnancy [4].

An anencephaly account in $50 \%$ of case is associated with hydramnios which may lead to high frequency of late abortions and premature labor [5], [6]. This hydramnios with is explained by difficulty of swallowing amniotic fluid by the fetus is more frequently found in bichorionic pregnancy than monochorionic [7]. Others complications that occurred in monochorionic pregnancy with the increased risk of intra-uterine death or severe brain damage due probably to exsanguination after the death of the anencephalic twin [8].

There are two therapeutic options for anencephaly: the expectative option or selective exclusion of malformed fetus [3]. The diagnosis must be earlier through the first trimester echography to permit the choice of one between the two methods with the consent of parents. The first strategy was the only option in our country because of non-developed fetal medicine. This option has a high risk of hydramnios, a frequency of $50 \%$, most mark when the pregnancy is dichorionic like found in our patient. The expectative approach exposes therefore to hydramnios and needs iterative amniotic punctures with all infectious, serologic and bleeding risks [3].
The second treatment option is the selective feticid. This procedure consists in the interruption of one fetus within a multiple pregnancy after the first trimester [9]. It can be made by different technical methods depending on the chorionicity. In dichorionic pregnancy, because of absence of vascular anatomosis, we can use a drug that causes cardiac arrest without affecting the other twin [9]. These drugs can be potassium chlorid or lidocaine whichare administrated directly in heart or in cord [9]. In Monochorionic pregnancy, we can coagulate, compress or stich of the cord [9]. It was proven that selective feticidereduce the neonatal mobi-mortality of the non malformed fetus and reduces the risk of psychologic trauma of the parents [3]. The complications of these procedures are mainly abortion which represents $3-16 \%$ of pregnancies [10]. This depends on the technique, the term and experience of the practitioner [10]. For our patient like in most similar cases reported in literature, the expectative technique has a poor outcome than selective feticide [4]. Other studies that compare the two attitude show that expectancy management are associated to the low gestational age at birth and with low birth weight than active management of the pregnancy [3]. This study reveals that the mid duration of the pregnancy was 38 weeks in feticide group and 34.9 weeks in expectancy management in dichorionic pregnancy. Recent studies showed that there was no difference in the both treatment in term of fetal mortality, but the lower risk of premature child in the feticide group [11]. In fact, we keep in mind that in these studies, the expectancy group has benefited of amniodrainage in case of hydramnios, which may explain the non inferiority of this technical approach. But in our context we have lack of scientific experience and material to apply this technic in several hospitals. Amadaou et al in a cases series found that on 6 cases of anencephaly managed by 
expectative approach, the intra-uterin death of both twin dead occurs in 4 cases [4]. This result is due to the fact that any action like amniodrainage was not did, this reflect the reality of most hospital in low income countries.

\section{Conclusion}

Anencephaly of one twin is one the most frequent malformation in multiple pregnancies. The major risk factor identify in our patient was the absence of folic acid supplementation. It is associated with less good outcome notably in lows income countries where fetal medicine is not developed.

\section{Acknowledgements}

The authors are solely responsible for this manuscript preparation and decision to submit it for publication.

\section{Funding}

The authors did not receive any funding for this research.

\section{Availability of Data and Materials}

The authors declare that all data concerning this case report are provided within the manuscript.

\section{Authors' Contributions}

RM, JDS, EM, BS, PF managed the patient. RM drafted the initial manuscript which was modified by MNT. All authors read and approved the final manuscript.

\section{Ethics Approval and Consent to Participate}

Our institution does not require ethics approval for case reports.

\section{Consent for Publication}

Written informed consent was obtained from the patient for publication of this case report and any accompanying images. A copy of the written consent is available for review by the Editor-in-chief of this journal.

\section{Competing Interests}

The authors declare that there are no competing interests.

\section{References}

[1] Grignon A, Dubois J. Echographie des grossesses gémellaires. Journal de radiologie. 2002;83: 1899-908.

[2] Mohammed. A, Naima. C, Loubna. B. Epidémiologie et facteurs de risque des anomalies de fermeture du tube neural: données marocaines. Panafrican Medical Journal. 2015; 22:43.

[3] Annelies Lust, Luc De Catte, Liesbeth Lewi. Monochorionic and dichorionic twin pregnancies discordant for fetal anencephaly: a systematic review of prenatal management options. Prenat Diagn. 2008; 28: 275-279.

[4] Amadou A, Sonhaye L, Douaguibe B. Anencéphalie sur grossesse gémellaire: une série de six cas; Medecine et Sante' Tropicales. 2013; 23: 185-188.

[5] Mohammed Amine Radouani1, Naima Chahid1, Loubna Benmiloud et alEpidémiologie et facteurs de risque des anomalies de fermeture du tube neural: données marocaines. Panafrican Medical Journal;2015; 22:43.

[6] Lipitz S, Meizner I, Yagel S, Shapiro I, Achiron R, Schiff E. Expectant management of twin pregnancies discordant for anencephaly. ObstetGynecol. 1995; 86:6; 969-972.

[7] Gaigi SS, Aida M, Sami J. Aspects foetopathologiques de 97 cas d'anencephalie: Etude du CMNR Tunis. Tunis Med. 2000; 78: 653-7.

[8] Robyr R, Yamamoto M, Ville Y. Selective fetocide in complicated monochorionic twin pregnancies using ultrasoundguided bipolar coagulation. British journal of obsteric and gynaecology. 2005; 112: 1344-1348.

[9] Delabaere A, Lemery D, Laurichesse H. J Gynecol Obstet Biol Reprod. 2010;39:S1-S342.

[10] Eddleman KA, Stone JL, Lynch L, Berkowitz RL. Selective termination of anomalous fetuses in multifetal pregnancies: two hundred cases at a single center. Am J ObstetGynaecol. 2002; 187: 1168-1172.

[11] De la Calle M, Arrieta S, Herro B. Dichorionic twin pregnancy discordant for anacephaly: two cases with different management; ClinExpObstet Gynecol. 2014; 41(2): 208-10. 